\title{
Correction to: Gabapentin as add-on to morphine for severe neuropathic or mixed pain in children from age 3 months to 18 years - evaluation of the safety, pharmacokinetics, and efficacy of a new gabapentin liquid formulation: study protocol for a randomized controlled trial
}

Thomas G. de Leeuw ${ }^{1 *}$, Laura Mangiarini², Rebecca Lundin ${ }^{3}$, Florentia Kaguelidou ${ }^{4,5,6}$, Tjitske van der Zanden ${ }^{7}$, Oscar Della Pasqua ${ }^{8}$, Dick Tibboel ${ }^{7}$, Adriana Ceci ${ }^{2}$, Saskia N. de Wildt ${ }^{7,9}$ and on behalf of the GAPP consortium

Correction to: Trials (2019) 20:49.

https://doi.org/10.1186/s13063-018-3169-3

Following publication of the original article [1], we have been notified that the tagging of one of the author names was done incorrectly in the XML version of the paper. Original and corrected tagging can be seen below.

- Incorrect name tagging: Last Name: Pasqua. First Name: Oscar Della.

- Correct author name tagging: Last Name: Della Pasqua.

First Name: Oscar.
Received: 12 June 2019 Accepted: 12 June 2019

Published online: 20 June 2019

\section{Reference}

1. Leeuw, et al. Gabapentin as add-on to morphine for severe neuropathic or mixed pain in children from age 3 months to 18 years - evaluation of the safety, pharmacokinetics, and efficacy of a new gabapentin liquid formulation: study protocol for a randomized controlled trial. Trials. 2019;20:49. https://doi.org/10.1186/s13063-018-3169-3.

Author details

'Department of Anesthesia and Pain Medicine, Erasmus MC-Sophia Children's Hospital, Dr. Molewaterplein 40, 3015 GD Rotterdam, The Netherlands. ${ }^{2}$ Consorzio per Valutazione Biologiche e Farmacologiche, Pavia, Italy. ${ }^{3}$ Fondazione Penta Onlus, Padova, Italy. ${ }^{4}$ Department of Pediatric Pharmacology and Pharmacogenetics, AP-HP, Hôpital Robert Debré, F-75019 Paris, France. ${ }^{5}$ Inserm, CIC 1426, F-75019 Paris, France. ${ }^{6}$ Université Paris Diderot, Sorbonne Paris Cité, EA 08, F-75010 Paris, France. ${ }^{7}$ Intensive Care and Department of Paediatric Surgery, Erasmus MC-Sophia Children's Hospital, Dr. Molewaterplein, 403015 GD Rotterdam, The Netherlands. ${ }^{8}$ University College London, London, UK. ${ }^{9}$ Department of Pharmacology and Toxicology, Radboud University, Nijmegen, The Netherlands.

\footnotetext{
* Correspondence: t.deleeuw@erasmusmc.nl

${ }^{1}$ Department of Anesthesia and Pain Medicine, Erasmus MC-Sophia Children's Hospital, Dr. Molewaterplein 40, 3015 GD Rotterdam, The Netherlands

Full list of author information is available at the end of the article
}

(c) The Author(s). 2019 Open Access This article is distributed under the terms of the Creative Commons Attribution 4.0 International License (http://creativecommons.org/licenses/by/4.0/), which permits unrestricted use, distribution, and reproduction in any medium, provided you give appropriate credit to the original author(s) and the source, provide a link to the Creative Commons license, and indicate if changes were made. The Creative Commons Public Domain Dedication waiver (http://creativecommons.org/publicdomain/zero/1.0/) applies to the data made available in this article, unless otherwise stated. 